\title{
Gastric Lipoma Revealed By Digestive Bleeding
}

\author{
Sabbah Meriam ${ }^{*}$, Helal Imen ${ }^{1}$, Haddad Dhafer ${ }^{2}$, Bellil Nawel ${ }^{3}$, Gargouri Dalila ${ }^{4}$ \\ ${ }^{1}$ Departement of gastroenterology. Habib Thameur Hospital, Tunisia \\ ${ }^{2}$ Departement of pathology. Habib Thameur Hospital, Tunisia \\ ${ }^{3}$ Departement of surgery. Habib Thameur Hospital, Tunisia
}

*Corresponding author: Sabbah Meriam, Departement of gastroenterology. Habib Thameur Hospital, Tunisia.

Received date: February 18, 2020; Accepted date: February 27, 2020; Published date: March 03, 2020

Citation: Meriam S., Imen H., Dhafer H., Nawel B., Dalila G. (2020) Gastric Lipoma Revealed By Digestive Bleeding . J Clinical Research and Reports, 3(3); DOI:10.31579/2690-1919/053

Copyright: (C) 2020 Sabbah Meriam, This is an open access article distributed under the Creative Commons Attribution License, which permits unrestricted use, distribution, and reproduction in any medium, provided the original work is properly cited

A 40 -year-old men presented to the emergency for digestive bleeding (hematemesis). Hemoglobin level was $11 \mathrm{~g} / \mathrm{dL}$ Upper endoscopy showed an ulcerated gastric submucosal tumor of 4 centimeters (Figure 1) of the antrum. CT scan found the gastric tumor which was hypodense and heterogenous and revealed no apparent metastasis (Figure 2).
Echoendoscopy confirmed the presence of submucosal hypergenic hetereogenous tumor mesasuring $4 \mathrm{~cm}$ seeming to develop on the 3 th layer (Figure 3). Mucosal biopsy was negative. Patient underwent surgery (partial gastrectomy). Histological examination confirmed the submucosal lipoma (Figure 4). Outcome was favorable after surgery.

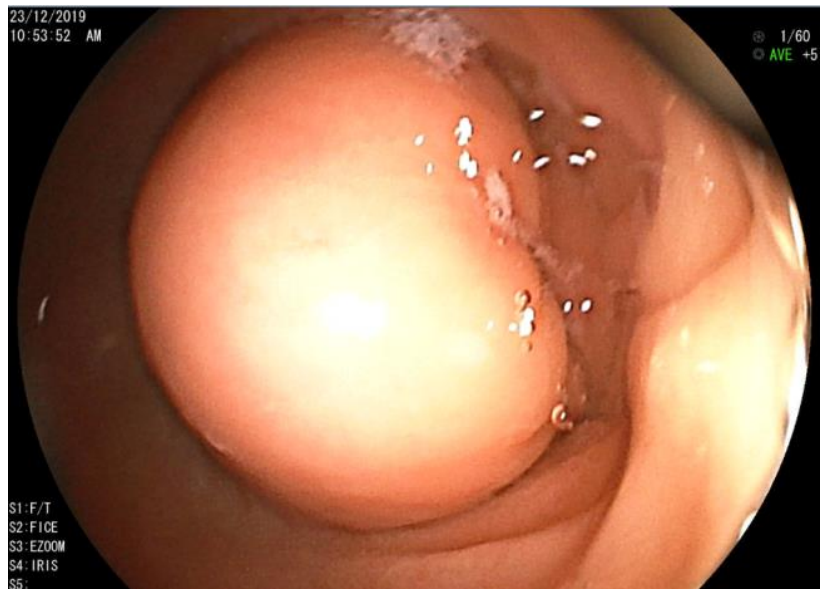

Figure 1: Endoscopic view: submucosal antral lesion of $4 \mathrm{~cm}$

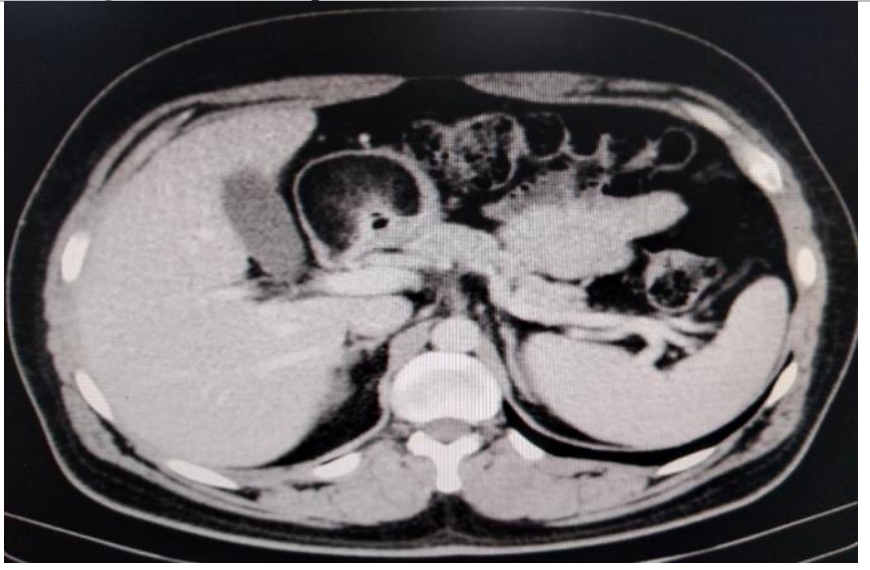

Figure 2: CT scan: the tumor is hypodense and heterogenous with no metastases 


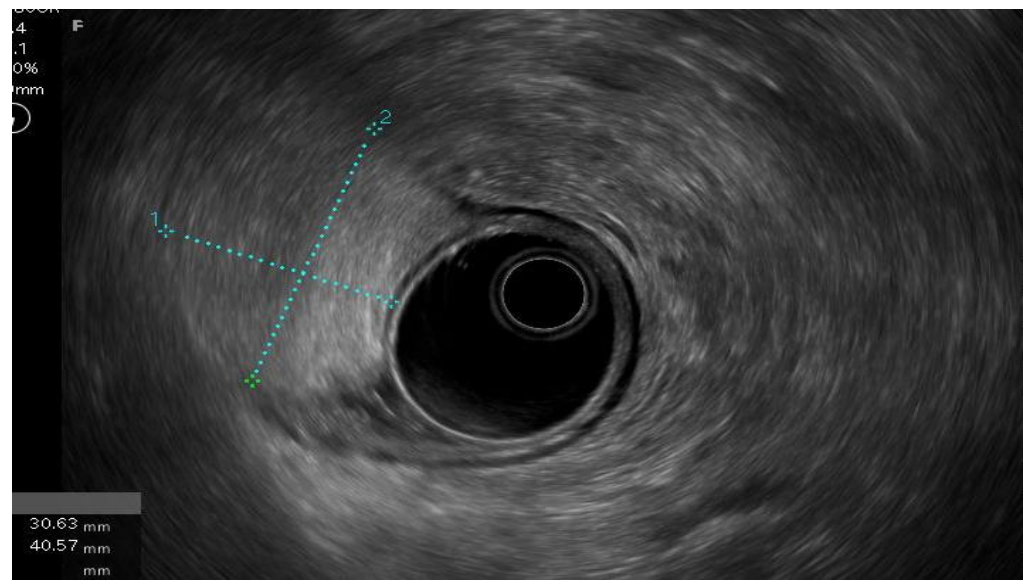

Figure 3: Echoendoscopy: submucosal hypergenic hetereogenous tumor mesasuring $4 \mathrm{~cm}$ seeming to develop on the 3 th layer

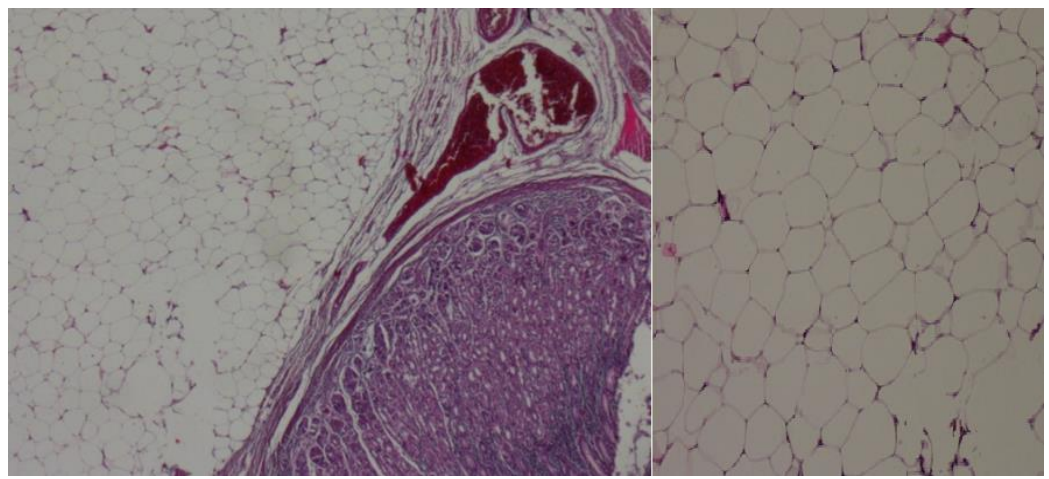

Figure 4: Histopathological examination: mature lipoma

\section{Conflicts of interest: None}

References

1. Termos S, Reslan O, Alqabandi O, AlDuwaisan A, Al-Subaie $S$ et al (2017) .Int J Surg Case Rep. ;41:39-42.

2. Cappell MS, Stevens CE, Amin M (2017) World J Gastroenterol. Aug 14;23(30):5619-5633.
3. Kohashi T, Itamoto T, Fukuda S, Yamasaki H, Yokoya H, et al (2006) Hiroshima J Med Sci. Dec;55(4):121-123.

4. Paksoy M, Böler DE, Baca B, Ertürk S, Kapan S et al (2005) Surg Laparosc Endosc Percutan Tech. Jun;15(3):163-165.

5. Roncolini G, Capaldi M, Calabrese P, Giordani M, Pietrafesa A et al (1999) Chir Ital. Nov-Dec;51(6):483-487.

6. Levasseur JC, Delavierre P, Vayre P.Sem Hop (1970) Apr 14;46(18):1204-1206.

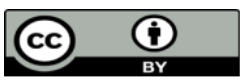

This work is licensed under Creative Commons Attribution 4.0 License

To Submit Your Article Click Here: Submit Article

DOI:10.31579/2690-1919/053 